\title{
Evolution of transoral approaches, endoscopic endonasal approaches, and reduction strategies for treatment of craniovertebral junction pathology: a treatment algorithm update
}

\author{
Brian J. Dlouhy, MD, ${ }^{1}$ Nader S. Dahdaleh, MD, ${ }^{2}$ and Arnold H. Menezes, MD1 \\ 1Department of Neurosurgery, University of lowa Hospitals and Clinics, lowa City, lowa; and 2Department of Neurological \\ Surgery, Feinberg School of Medicine, Northwestern University, Chicago, Illinois
}

\begin{abstract}
The craniovertebral junction (CVJ), or the craniocervical junction (CCJ) as it is otherwise known, houses the crossroads of the CNS and is composed of the occipital bone that surrounds the foramen magnum, the atlas vertebrae, the axis vertebrae, and their associated ligaments and musculature. The musculoskeletal organization of the CVJ is unique and complex, resulting in a wide range of congenital, developmental, and acquired pathology. The refinements of the transoral approach to the CVJ by the senior author (A.H.M.) in the late 1970s revolutionized the treatment of CVJ pathology. At the same time, a physiological approach to CVJ management was adopted at the University of lowa Hospitals and Clinics in 1977 based on the stability and motion dynamics of the CVJ and the site of encroachment, incorporating the transoral approach for irreducible ventral CVJ pathology. Since then, approaches and techniques to treat ventral CVJ lesions have evolved. In the last 40 years at University of lowa Hospitals and Clinics, multiple approaches to the CVJ have evolved and a better understanding of CVJ pathology has been established. In addition, new reduction strategies that have diminished the need to perform ventral decompressive approaches have been developed and implemented.

In this era of surgical subspecialization, to properly treat complex CVJ pathology, the CVJ specialist must be trained in skull base transoral and endoscopic endonasal approaches, pediatric and adult CVJ spine surgery, and must understand and be able to treat the complex CSF dynamics present in CVJ pathology to provide the appropriate, optimal, and tailored treatment strategy for each individual patient, both child and adult. This is a comprehensive review of the history and evolution of the transoral approaches, extended transoral approaches, endoscopic assisted transoral approaches, endoscopic endonasal approaches, and CVJ reduction strategies. Incorporating these advancements, the authors update the initial algorithm for the treatment of CVJ abnormalities first published in 1980 by the senior author.
\end{abstract}

http://thejns.org/doi/abs/10.3171/2015.1.FOCUS14837

KEY WORDS craniovertebral junction; craniocervical junction; transoral approach; transpalatopharyngeal approach; odontoidectomy; reduction; distraction; basilar invagination; atlas assimilation

$\mathrm{T}$ HE craniovertebral junction (CVJ), or the craniocervical junction as it is otherwise known, is composed of the occipital bone that surrounds the foramen magnum, the atlas vertebrae, the axis vertebrae, and their associated ligaments and musculature. ${ }^{73}$ The CVJ contains the cervicomedullary junction $(\mathrm{CMJ})$ and its associated blood supply - the ascending vertebral arteries that pass through the foramen magnum and form the basilar artery. The CMJ is the crossroads of the CNS as the brainstem transitions to the upper cervical spinal cord. The medulla contains the nuclei required for breathing and cardiovascular function, and the CMJ contains the descending motor fibers to the spinal cord and ascending sensory fibers. Therefore, the CVJ houses the essential functions of life.

The complex musculoskeletal organization of the CVJ is unique in comparison with the rest of the cervical spine in regard to bony anatomy and joint configuration, shape, and orientation. ${ }^{73}$ This sophisticated arrangement of structures is critical to allow complex movements of the head and neck and to provide protection of the critical areas

ABBREVIATIONS CMJ = cervicomedullary junction; CVJ = craniovertebral junction; EEA = endoscopic endonasal approach; MLG = median labiomandibular glossotomy; OC = occiput; VPI = velopharyngeal insufficiency.

SUBMITTED December 1, 2014. ACCEPTED January 27, 2015.

INCLUDE WHEN CITING DOI: 10.3171/2015.1.FOCUS14837.

DISCLOSURE The authors report no conflict of interest concerning the materials or methods used in this study or the findings specified in this paper. 
of the brainstem and upper cervical spinal cord. However, this complexity also creates the potential for a wide range of congenital, developmental, and acquired pathology. ${ }^{78}$ Given the critical neural structures contained within the $\mathrm{CVJ}$, pathology creating bony and ligamentous instability or mass effect causing compression of these neural structures can result in significant impairment. Direct surgical access to the CVJ is of paramount importance for decompression and establishing stability. ${ }^{77}$

The treatment of CVJ pathology has undergone remarkable evolution and advancements over the last 100 years. Depending on the location of pathology, surgical approaches to the CVJ are divided into those that use the ventral, lateral, and dorsal approaches (Table 1). ${ }^{74}$ The transoral approaches for decompression of irreducible ventral pathology at the CVJ have become a mainstay of treatment. In the last 10 years, the emergence of endoscopic endonasal approaches (EEAs) ${ }^{47}$ has provided more options for decompression of irreducible ventral CVJ pathology. Additionally, various reduction strategies have evolved. The ability to properly reduce ventral CVJ lesions and avoid a ventral approach has increased over the last 40 years due to improvements in occipitocervical instrumentation, ${ }^{59,78}$ preoperative and intraoperative imaging, ${ }^{14,15}$ and a better understanding of CVJ pathology. Over the last 40 years at the University of Iowa Hospitals and Clinics, more than 6000 children and adults have been treated for wide-ranging CVJ pathology and more than 800 transoral procedures have been performed for irreducible ventral CVJ pathology. ${ }^{8,14,15,24,25,33,57,58,60-67,69-72,74-78,85,86,91,93,97}$ Here we discuss the evolution of the transoral approaches, EEAs, and reduction strategies for the treatment of CVJ pathology. Incorporating these advances, we update the algorithm used to treat

TABLE 1. Surgical approaches to the CVJ

\begin{tabular}{|c|}
\hline Ventral \\
\hline Midline \\
\hline Standard transoral \\
\hline Transoral-transpharyngeal \\
\hline Transoral-transpalatopharyngeal \\
\hline Extended transoral \\
\hline Median labiomandibular w/ or w/o glossotomy \\
\hline Le Fort I osteotomy w/ down-fracture of maxilla \\
\hline Le Fort I osteotomy w/ palatal split \\
\hline Le Fort II osteotomy \\
\hline Transpalatal \\
\hline Endoscopic endonasal \\
\hline Lateral \\
\hline Lateral transcervical extrapharyngeal \\
\hline Lateral \\
\hline Extreme lateral-lateral transcervical transcondylar \\
\hline Dorsal \\
\hline Midline \\
\hline Suboccipital w/ PF \& cervical midline decompression \\
\hline Lateral \\
\hline Far lateral-lateral suboccipital transcondylar \\
\hline
\end{tabular}

CVJ pathology, which was first published in 1980 by the senior author (A.H.M.) (Fig. 1). ${ }^{71,77}$

\section{Transoral Approaches to the CVJ-Historical Beginnings}

Recognizing that a lateral approach would not provide adequate access to remove a bullet lodged between the atlas and the clivus and that the most direct approach to the ventral CVJ (lower clivus, atlas, and axis) was via the mouth and posterior pharynx, in 1917 Kanavel was first to describe the transoral-transpharyngeal approach to the CVJ ${ }^{45}$ In 1957, Southwick and Robinson resected an osteoma of the body of the axis through a transoral-transpharyngeal approach. ${ }^{92}$ However, it wasn't until 1962 that Fang and Ong described the approach in detail, using it in 5 cases of chronic irreducible atlantoaxial dislocations and 1 case of tuberculosis of the atlas and axis. ${ }^{23}$ In this small series the complication rate was high, with 4 cases resulting in infection and 1 infection leading to death. However, in their discussion of the approach, Fang and Ong thought that infection could be reduced with meticulous closure of the posterior pharyngeal wall, proper preoperative oral preparation, and preoperative and postoperative antibiotics. ${ }^{23}$ Despite this discussion and understanding, the approach was only used sporadically in case reports in the $1960 \mathrm{~s}^{7,32}$ and early 1970s. ${ }^{6,94}$ In these reports, refinement of the procedure and the development and widespread availability of the operating microscope helped limit complications, and the approach proved effective for lesions at the ventral CVJ.

It wasn't until the late 1970s that Arnold H. Menezes (the senior author) continued refinement of the transoral approach by using extensive preoperative oropharynx preparation; preoperative and postoperative antibiotics; thorough perioperative management; precise microscopic dissection through the soft palate, posterior pharyngeal wall, and longus colli and longus capitis muscles (Fig. 2); and a meticulous multilayered posterior pharyngeal wall and soft-palate closure (Fig. 3). ${ }^{71,77}$ In Menezes and colleagues' 1980 report, ${ }^{77} 9$ of 17 patients underwent a transoral approach for congenital, developmental, and acquired CVJ pathology. ${ }^{71}$ No postoperative infections occurred and complications were minimal. This was the first large series that demonstrated that the transoral approach was not fraught with complications as suggested by the series from Fang and Ong. ${ }^{23}$ This was found to be true in both children $^{71}$ and adults. ${ }^{77}$ This report also ignited a new era in CVJ treatment. In this same report, Menezes proposed an algorithm for CVJ pathology based on the stability and motion dynamics of the CVJ as well as the reducibility and site of encroachment, incorporating the transoral approach for treatment of irreducible ventral CVJ pathology. This algorithm continues to hold true to this day and is often referred to when discussing treatment of CVJ pathology (Fig. 1).

In 1988, Menezes and VanGilder reported on 72 transoral cases treated over a period of 10 years-the largest series to date at that time. Given the minimal complications (only 1 pharyngeal infection treated with antibiotics) and substantial neurological improvement in these 72 children 


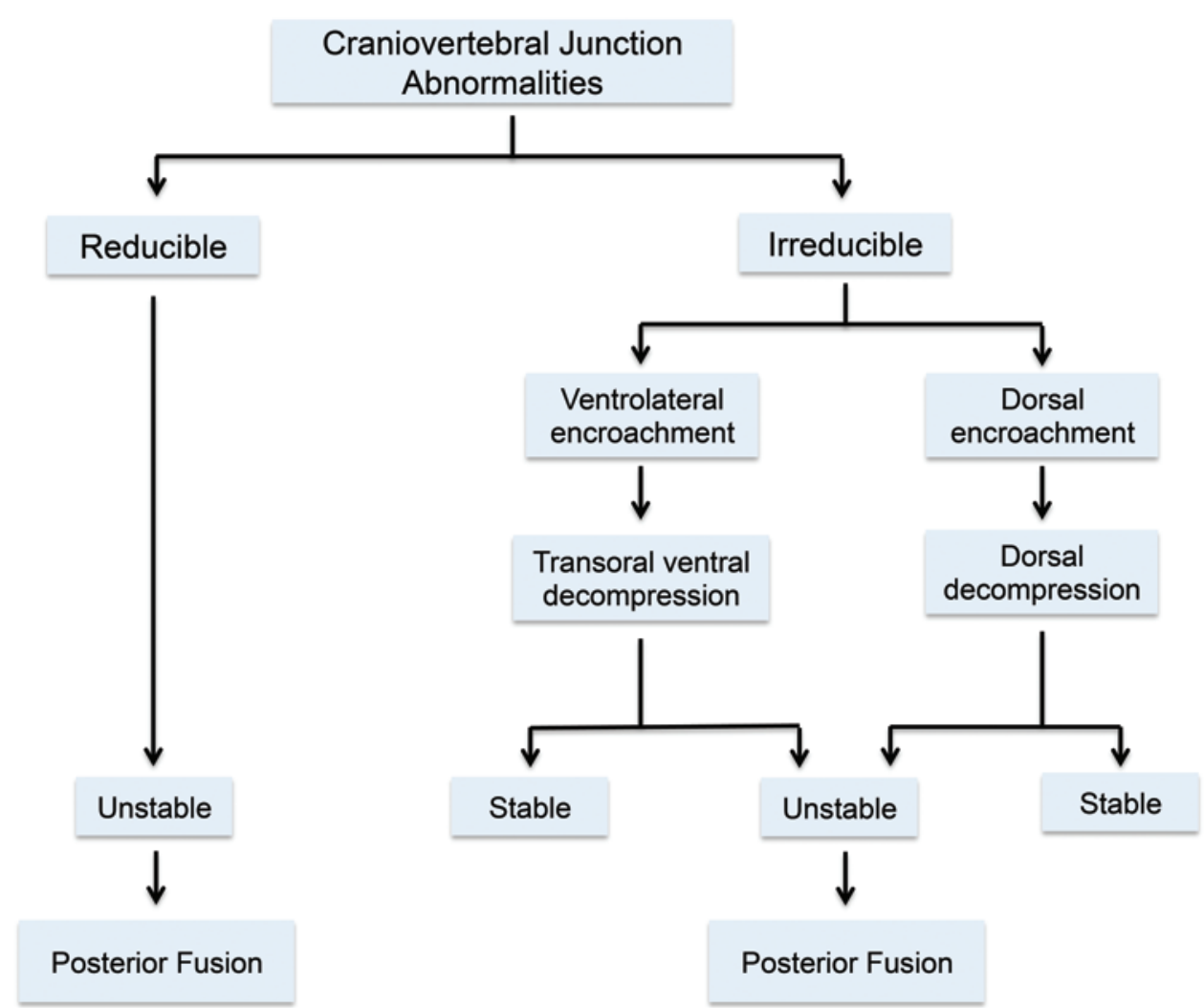

FIG. 1. Initial CVJ treatment algorithm. This approach to CVJ pathology was published in 1980 and is based on the stability and motion dynamics of the CVJ as well as the reducibility and site of encroachment, incorporating the transoral approach for treatment of irreducible ventral CVJ pathology. These concepts and this algorithm continue to hold true. If a lesion is reducible, whether with skeletal traction, intraoperative reduction distraction, or intraoperative traction, a ventral decompressive approach is not needed. Modified with permission from Menezes et al.: J Neurosurg 53:444-455, 1980.

and adults, the transoral approach became a mainstay in treating irreducible ventral CVJ pathology. ${ }^{75}$ It also established the operative nuances for $\mathrm{C}-1$ anterior arch resection and odontoidectomy (Fig. 2D-I), key principles used today in both transoral and endoscopic endonasal odontoidectomies. Subsequently, the report of 14 transoral cases by Crockard and colleagues in $1985^{10,12}$ and 53 transoral cases by Hadley, Sonntag, and Spetzler in $1989^{35}$ helped solidify the approach. The standard transoral approach as popularized by the pioneers mentioned above include the transoral-transpharyngeal approach and the transoraltranspalatopharyngeal approach (Table 1).

\section{Transoral-Transpalatopharyngeal (Standard Transoral) Approach Degree of CVJ Exposure}

The transoral-transpharyngeal approach provides exposure from the clivus to the $\mathrm{C} 2-3$ interspace and laterally for $2 \mathrm{~cm}$ to either side of the midline (Table 2). Laterally situated lesions may involve the occipital condyles as well as the lateral portions of the posterior fossa, the transverse processes of the atlas, and the axis vertebrae. A midline ventral approach allows exposure of the anterior $45^{\circ}$ of the circumference of the foramen magnum to either side of the midline, thus providing a $90^{\circ}$ exposure.

We prefer to divide the soft palate (transoral-transpala- topharyngeal approach) (Fig. 2D-I) when needed because it increases exposure superiorly to the inferior one-third of the clivus (Table 2). Many others have suggested that elevation and retraction of the soft palate provides similar access for its division. However, with normal clival anatomy we have found that elevation and retraction of the soft palate usually only provides rostral access to the inferior tip of the clivus. Additionally, in congenital pathological states such as with a foreshortened clivus or basioccipital hypoplasia, the clivus tends to be more horizontal in position than vertical. Thus, it becomes essential to divide the soft palate (transoral-transpalatopharyngeal approach) and at times resect the posterior inferior portion of the posterior hard palate to gain clival exposure. ${ }^{69}$ In this manner, the upper portion of the clivus can be visualized. Anatomical studies have confirmed our clinical findings. In an anatomical cadaver study by Balasingham et al., ${ }^{4}$ division of the soft palate provided nearly $1 \mathrm{~cm}$ of clival exposure. In contrast, retraction of the soft palate into the nasopharynx did not provide adequate exposure of the clivus superior to the foramen magnum, but did provide adequate exposure of the atlantoaxial complex. In general, a review of imaging studies preoperatively is integral to deciding on the adequacy of clival exposure with or without a soft-palate split, and on whether this exposure is even needed for ventral decompression.

The inferior extent of the exposure, which is limited by 


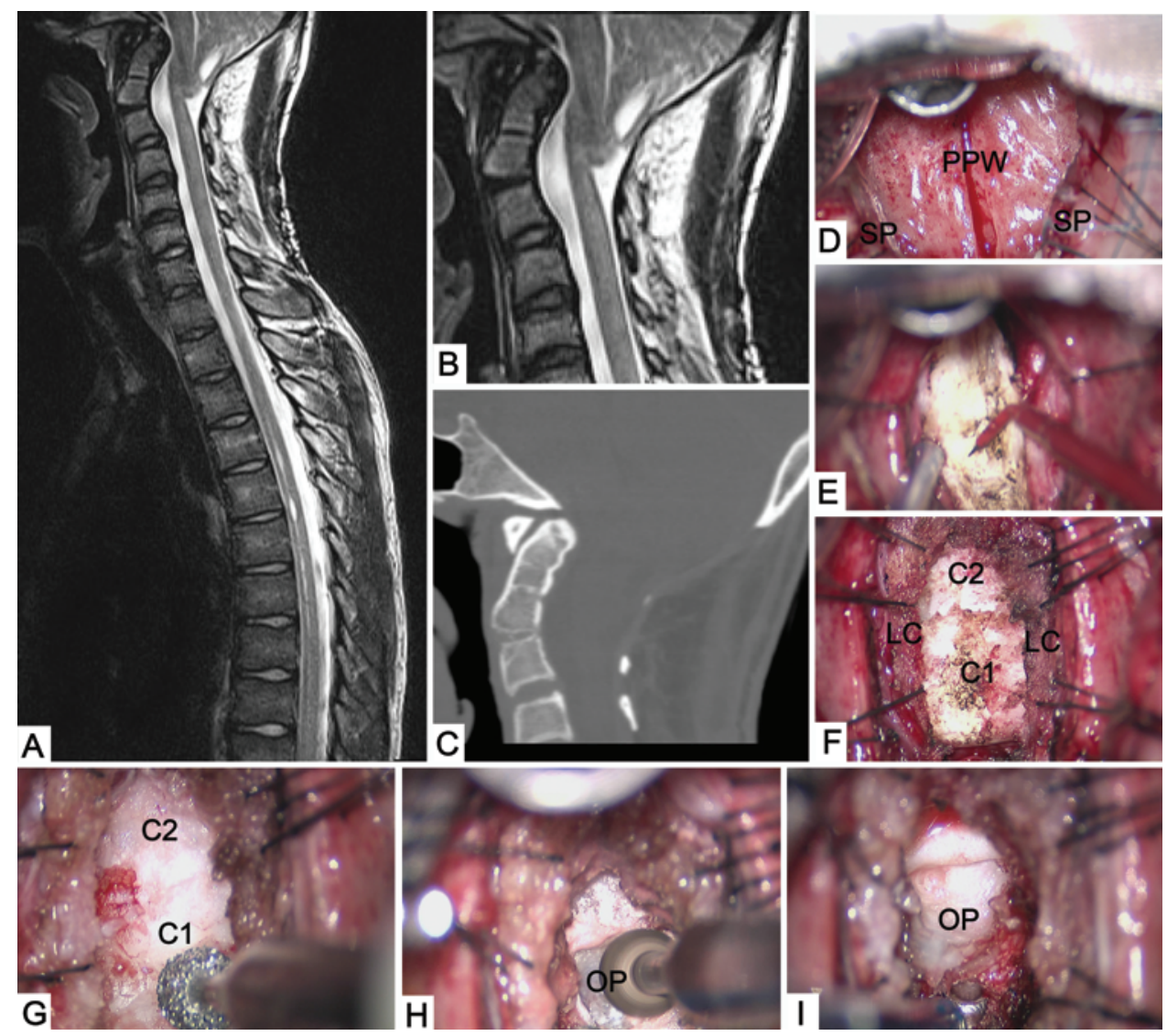

FIG. 2. Transoral-transpalatopharyngeal approach to the CVJ for odontoidectomy. Cervicothoracic T2-weighted MRI demonstrating a Chiari Type I malformation and a 3.3-mm cervicothoracic syrinx (A). Cervical T2-weighted MRI demonstrating the clivus odontoid articulation indenting the ventral medulla and tonsillar herniation to the level of C-2 compressing the dorsal medulla (B). Sagittal CT demonstrating basilar invagination with retroflexed odontoid, platybasia, and clivus-canal angle of $101^{\circ}$ (C). D-I: Intraoperative photographs. The soft palate (SP) was divided to the right of the uvula and stay sutures were placed, exposing the posterior pharyngeal wall (PPW) (D). The posterior pharyngeal wall was sharply divided using sharp monopolar cautery and the mucosa was divided (E). The longus capitis and longus colli (LC) muscles were divided in the midline and dissected laterally in a subperiosteal manner. The posterior pharyngeal wall and longus capitis and longus colli muscles were held back and in place with stay sutures to allow proper exposure of the anterior arch of C-1, the midline tubercle of $\mathrm{C}-1$, and the $\mathrm{C}-2$ body $(\mathrm{F})$. The anterior arch of C-1 was cored out with a high-speed drill and the posterior aspect of C-1 was removed with curettes to allow exposure of the odontoid process (G). The odontoid process (OP) was removed using a high-speed drill (H) and curettes (I). Note: microscope views are from the surgeon's perspective at the top of the patient's head.

the degree of depression of the tongue, is the $\mathrm{C} 2-3$ interspace. The lateral extent of the exposure is limited by the condylar canals of the hypoglossal nerve, the eustachian tubes, and the vertebral arteries before they enter into the intradural space. However, when a tumor-such as a chordoma-is present, the tumor displaces normal anatomy, creating working space and greater exposure than normal.

\section{Indications for Standard Approach}

The initial algorithm (Fig. 1 $)^{71,77}$ for the treatment of CVJ pathology continues to hold true 35 years after initial publication and defines when to use a transoral or other appropriate anterior approach for ventral CVJ decompression. Reduction pertains to the reestablishment of anatomical alignment to relieve compression of neural structures. ${ }^{77}$ If the ventral lesion is irreducible, an anterior approach is required for decompression, which then often necessitates posterior instrumentation and fusion. If the lesion is reducible, a ventral transoral approach can be avoided and dorsal instrumentation and fixation can be performed in the position used for reduction, with or without a posterior decompression. In the last 40 years, transoral procedures have been performed for a variety of irreducible ventral CVJ pathology. ${ }^{69}$ This includes congenital and developmental basilar invagination, ${ }^{30}$ basilar impression (acquired or secondary basilar invagination), cranial settling (rheumatological basilar invagination), ${ }^{76}$ proatlas segmentation abnormalities,$^{70}$ os odontoideum, tumors, rheumatological retroodontoid (occiput [Oc]-C2) pannus, ${ }^{75}$ calcium pyrophosphate deposition disease with retroodontoid (Oc-C2) pannus, ${ }^{24}$ and other rare congenital bony abnormalities. ${ }^{8,69}$

\section{Limitations of the Approach}

In some young children, the ability to sufficiently open the mouth is extremely limited. A working distance of $2.5-3 \mathrm{~cm}$ between the upper and lower incisor teeth is necessary. However, this is further assessed once the child is asleep and paralysis is induced by the anesthesiologist. 

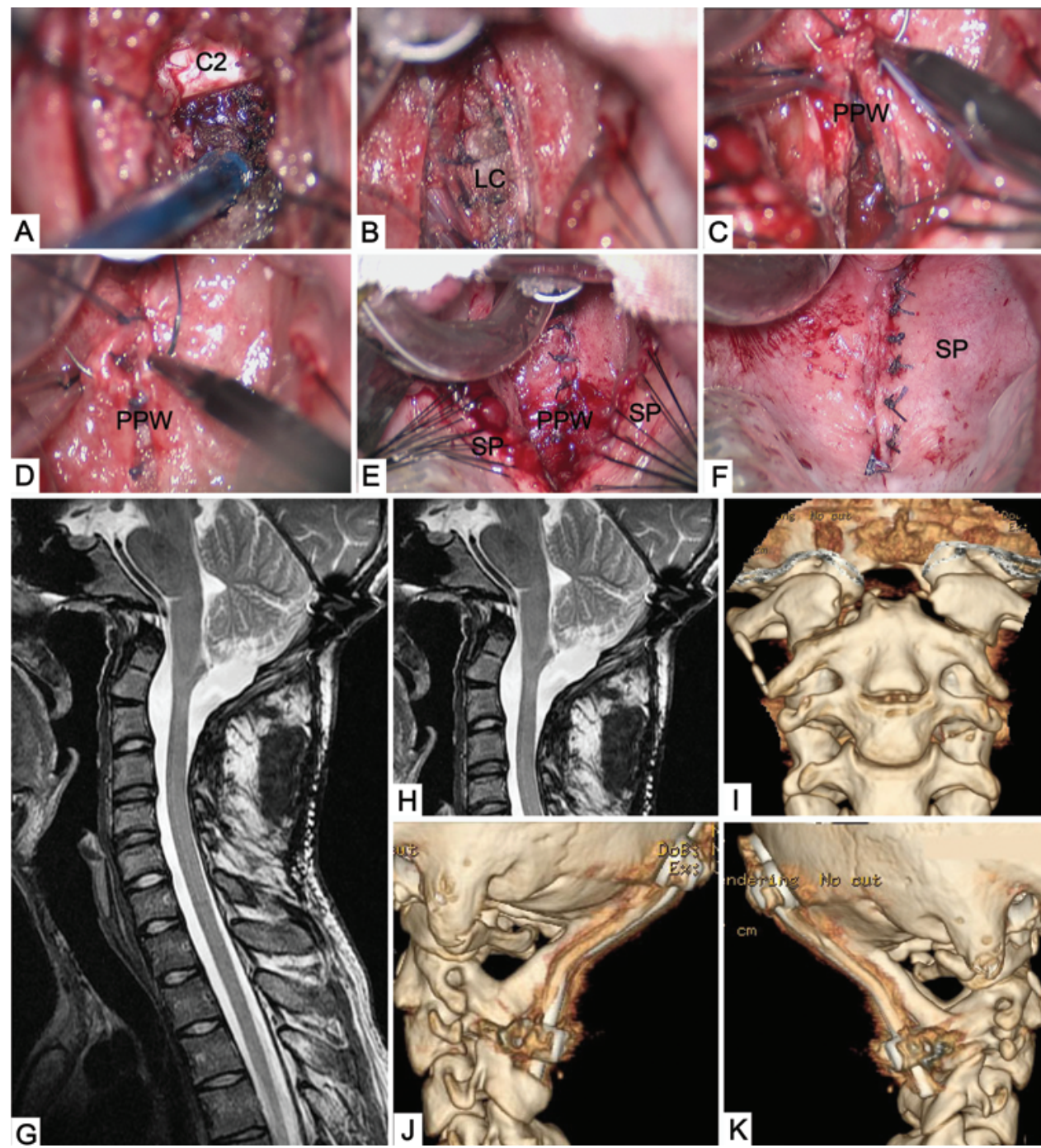

FIG. 3. Transoral-transpalatopharyngeal closure after odontoidectomy. After removal of the odontoid process and satisfactory decompression, hemostasis was achieved (A). The longus capitis and longus colli (LC) muscles were reapproximated in the midline by using Vicryl sutures (B). The posterior pharyngeal wall (PPW) was reapproximated using Vicryl sutures (C-E). The soft palate (SP) was reapproximated using Vicryl sutures (F). Postoperative cervicothoracic T2-weighted MRI demonstrating resolution of the tonsillar herniation and cervicothoracic syrinx (G). Postoperative cervical T2-weighted MRI demonstrating complete decompression of the medulla (H). Postoperative 3D CT scan revealing C-1 anterior arch resection and odontoidectomy (I). Left (J) and right (K) 3D CT scans revealing the occipitocervical fusion and osseous integration of rib graft bilaterally.

An extended transoral approach via the transmandibular route can be used in such extreme cases, but this is rare (see next section). ${ }^{8}$

\section{Illustrative Case}

A 16-year-old boy underwent a suboccipital craniectomy, C-1 laminectomy, intradural lysis of adhesions, and partial resection of the cerebellar tonsils at another institution when he was 5 years old. He presented to the senior author with progressive headaches and spasticity. Imaging revealed atlas assimilation, basilar invagination, C2-3 segmentation failure, Chiari Type I malformation, and newly developed syringomyelia. Due to the CVJ pathology and failure of the previous treatment, a transoraltranspalatopharyngeal approach was performed for resection of the anterior arch of $\mathrm{C}-1$, odontoid process, and medullary decompression (Figs. 2 and 3). After the transoral-transpalatopharyngeal odontoidectomy, a posterior fossa and upper cervical spine intradural lysis of adhesions was performed. This procedure consisted of opening of the fourth ventricle and foramen of Magendie, cervical fascia duraplasty, and $\mathrm{Oc}-\mathrm{C} 3$ fusion with occipitocervical plate, rod, and screw fixation with rib graft.

\section{Extending the Transoral Approach}

The emergence of the transoral approach provided exposure to a previously inaccessible region. Although this allowed proper decompression and treatment of a variety of CVJ pathologies, the approach was still limited in its exposure below the $\mathrm{C} 2-3$ interspace and above the inferior one-third aspect of the clivus. Combining the standard 
TABLE 2. Exposure provided by standard and extended transoral and endoscopic transnasal approaches

\begin{tabular}{lll}
\hline \multicolumn{1}{c}{ Approach } & \multicolumn{1}{c}{ Rostral Exposure } & \multicolumn{1}{c}{ Caudal Exposure } \\
\hline Standard transoral & & \\
\hline \multicolumn{1}{c}{ Transoral-transpharyngeal } & Inferior tip of clivus & C2-3 interspace \\
\hline Transoral-transpalatopharyngeal & Inferior $1 / 3$ of clivus & C2-3 interspace \\
\hline Extended transoral & & \\
\hline Median labiomandibular & Inferior $1 / 3$ of clivus & C3-4 interspace \\
\hline Median labiomandibular w/ glossotomy & Inferior $1 / 3$ of clivus & C4-5 interspace \\
\hline Le Fort I osteotomy w/ down-fracture of maxilla & Superior aspect of clivus & C-1 \\
\hline Le Fort I osteotomy w/ palatal split & Superior aspect of clivus & C2-3 interspace \\
\hline Endoscopic endonasal & Anterior fossa floor/sella/superior clivus & Determined by nasopalatine line \\
\hline
\end{tabular}

transoral approach with previously described techniques of craniofacial osteotomies that split the mandible and divided the tongue ${ }^{55,89}$ or opened the maxilla and divided the hard palate ${ }^{20}$ enhances access inferiorly to the C4-5 interspace and superiorly to the upper aspect of the clivus, respectively (Table 2). We consider these to be "extended transoral approaches." 105 The transmandibular approaches specifically include variations of the median labiomandibular approach, which consists of a mandibulotomy (division of the mandible) with or without a glossotomy (division of tongue). ${ }^{55,89}$ The transmaxillary approaches include the Le Fort I osteotomy with so-called down-fracture of the maxilla and the Le Fort I osteotomy with palatal split. Other approaches, which are rarely used in practice due to advances in endoscopic techniques, but have been described in the literature, ${ }^{50}$ include the transnasomaxillary approach, which uses a Le Fort II osteotomy, and a transpalatal approach in which a circumferential palatal osteotomy is performed. The principle of these extended technical variations is to extend the standard transoral approach and the empty anatomical spaces of the mouth and pharynx for greater rostral and caudal exposure of the CVJ.

\section{Transmandibular-Median Labiomandibular Approach and Variations}

A combined transoral-transpalatopharyngeal approach with a median mandibulotomy (median labiomandibular approach) allows for increased caudal exposure to the C3-4 interspace and maintains the superior exposure to the inferior one-third of the clivus. Dividing the tongue in the midline further increases the caudal exposure to the $\mathrm{C} 4-5$ interspace (median labiomandibular glossotomy [MLG] approach) $)^{2,8,17,79,98}$ (Fig. 4; Table 2).

Indications to use the MLG approach to augment exposure of the CVJ and the upper cervical vertebrae include an interincisor opening distance of less than $2.5 \mathrm{~cm}$ and when access to $\mathrm{C} 3-5$ is required (Fig. 4A). In children as well as adults, adequate access to the CVJ and upper cervical vertebrae can usually be achieved with a transoraltranspalatopharyngeal route. In some children, however, young age and/or small size preclude adequate exposure with a soft palatal split alone. Therefore, additional exposure can be gained with the MLG approach. However, this is a rare event. Tracheotomy allows an unobstructed view of the oral cavity and posterior pharyngeal wall and pre- vents upper airway obstruction secondary to tongue and pharyngeal edema in the perioperative phase.

The general advantages of the MLG include a wider surgical field in both transverse and sagittal dimensions (Fig. 4C). By splitting the mandible, the surgeon also has a shorter working distance to the spine (Fig. 4C-H). Disadvantages or risks in addition to the standard transoral risks include unfavorable facial scarring, oral incompetence, injury to developing permanent dentition, malocclusion, dysphagia, limited tongue mobility and sensation, mandibular duct injury, and complications of tracheostomy. However, these outcomes are uncommon and their risk is justified by the severity of the patient's neurosurgical condition. In general, with proper closure and good surgical technique, the facial scarring is minimal (Fig. $4 \mathrm{~J}$ and $\mathrm{K}$ ).

\section{Transoral Approach With MLG: Illustrative Case}

A 4-year-old boy with severe spondyloepiphyseal dysplasia congenita had severe ventral cervicomedullary compression secondary to retroflexion of the odontoid process and upper cervical bone abnormalities at $\mathrm{C}-2$, with cervical kyphosis and CVJ instability (Fig. 4). The standard transoral-transpalatopharyngeal approach would not provide sufficient exposure due to inadequate caudal exposure and due to the patient's young age and small size. Therefore, a transoral approach with MLG to the CVJ and upper cervical spine was performed for resection of the anterior body of C-2 and odontoid process. Rib graft was used for $\mathrm{Cl}-3$ anterior cervical fusion. Occipitocervical fusion was performed at a later date.

\section{Transmaxillary Approach}

\section{Le Fort I Osteotomy With Down-Fracture of Maxilla}

The Le Fort I osteotomy (maxillotomy) with down-fracture of the maxilla is an approach unto itself rather than an extension of the standard transoral approaches. ${ }^{88,96,100}$ A sublabial incision allows a horizontal osteotomy and down-fracture or inferior mobilization of the maxilla and hard palate to be performed. Others have described this approach as the "drop-down" maxillotomy approach. ${ }^{53}$ This approach provides access to the sphenoid sinus and superior and middle clivus; much greater superior exposure than what can often be achieved with a transoraltranspalatopharyngeal approach. However, the inferior displacement of the hard palate obstructs caudal access 


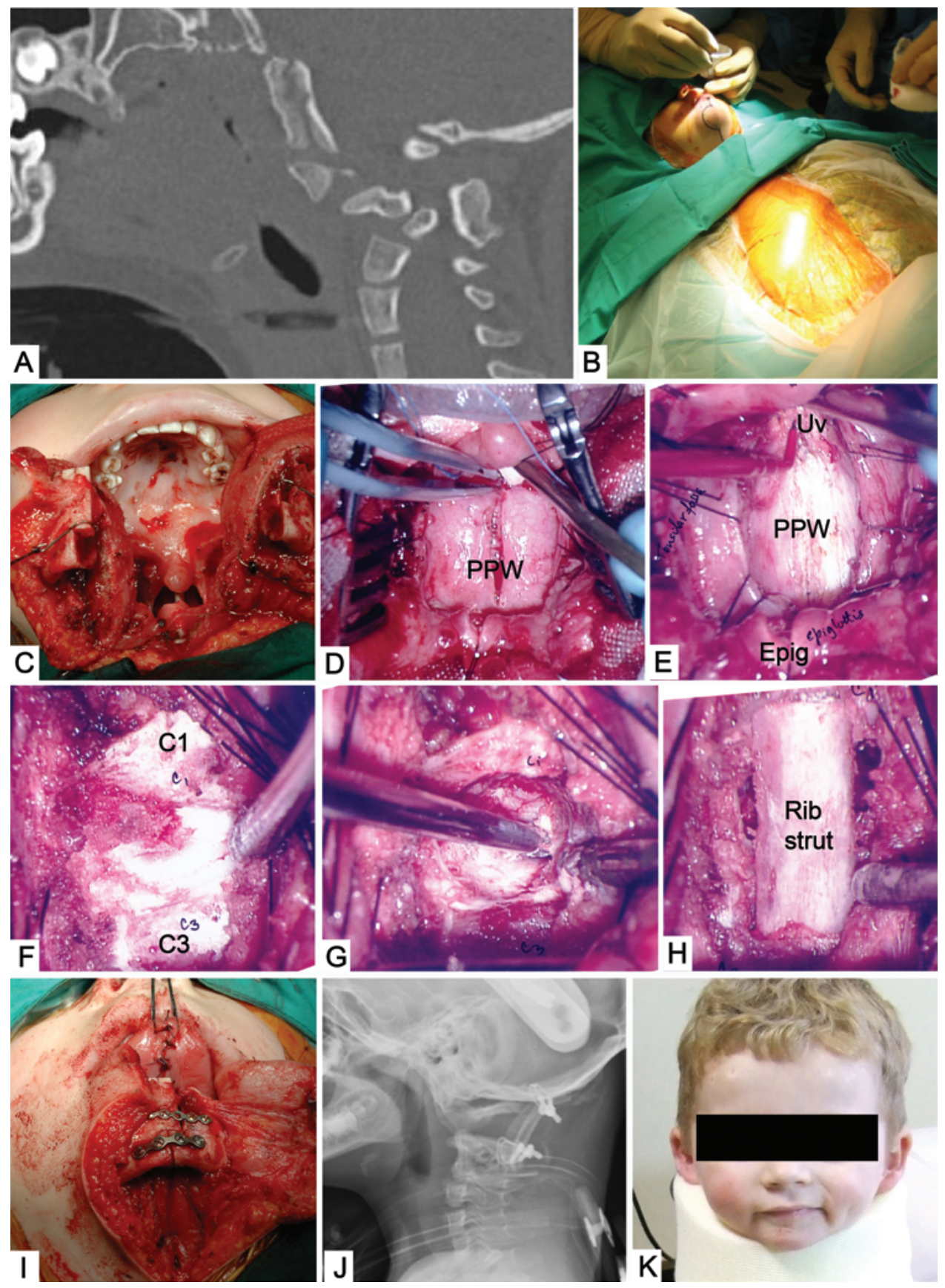

FIG. 4. Extended transoral approach with MLG for rare congenital CVJ bone abnormality (spondyloepiphyseal dysplasia congenita). Sagittal CT demonstrating craniocervical instability with Oc-C1 subluxation on C-2. Abnormal bone formation of C-2 is also seen, with retroflexed odontoid and severe compression of the cervical spine cord (A). The skin incision is made full thickness in the midline at the lip and sublabial crease and is carried around the mental protuberance, in a line of relaxed skin tension, and over the lower border of the mandible, back to midline, and extends inferiorly to the level of the hyoid (B). A mandibular osteotomy is performed and soft-tissue dissection within the floor of the mouth is continued in the midline between the submandibular ducts and carried into the intrinsic tongue musculature to expose the lingual surface of the epiglottis (Epig) to the level of the hyoid (C). The posterior pharyngeal wall (PPW) is divided in the midline and the C1-3 anterior vertebral bodies are exposed (D-F). The odontoid process and body of the odontoid is removed $(\mathbf{G})$ and harvested rib is used for interbody fusion $(\mathrm{H})$. Mandibular reconstruction is done using prefashioned rigid fixation plates (I). Postoperative cervical radiograph shows good interbody rib position, cervical alignment, and decompression (J). Photograph obtained 1 year later (K). The patient was neurologically intact and the skin incision was barely perceptible. Uv = uvula. 
to $\mathrm{C} 1-2$, which is the major limitation of this approach. An EEA can provide similar access above the hard palate without the morbidity of this approach. However, the Le Fort I osteotomy with down-fracture has advantages over the EEA in that it provides wider exposure as well as more inferior viewing past the plane of the hard palate.

The Le Fort I maxillotomy approach is indicated for extensive lesions that are too wide and too inferior for an EEA and too rostral for a standard transoral approach. However, with advancements of the EEA, the use of a Le Fort osteotomy is becoming increasingly rare.

\section{Le Fort I Osteotomy With Palatal Split}

The major limitation of the Le Fort I osteotomy with down-fracture is that the inferior displacement of the hard palate obstructs caudal access to $\mathrm{C} 1-2$. As mentioned above, this approach is not really an extended transoral approach because the extension from the mouth is not used to gain exposure. However, the Le Fort I osteotomy with palatal split is truly an extended approach. ${ }^{87}$ A horizontal osteotomy is performed along with a midline split of the hard and soft palate. ${ }^{87,99}$ This divides the maxilla in the midline, allowing the hemimaxilla to be mobilized laterally and extending the standard transoral-transpalatopharyngeal approach. Others have described this as the transmaxillary palatal split approach or the extended "open door" maxillotomy. ${ }^{42}$ It is essentially a Le Fort I osteotomy and, instead of down-fracturing the maxilla, it is divided in the midline and lateralized. This approach provides rostral exposure of the sphenoid sinus and superior and middle clivus while maintaining the inferior exposure provided by the standard transoral approaches to the C2-3 interspace.

The Le Fort I osteotomy with palatal split is indicated for extensive lesions from the superior aspect of the clivus to the body of C-2. However, with advancements in the EEA, the use of a Le Fort osteotomy is becoming increasingly rare. Even in rare cases of such an extensive lesion, an extended EEA is effective. The EEA is limited by the hard palate, but for extensive lesions from the top of the clivus to the body of C-2 and below the nasopalatine line, a combined EEA with a standard transoral approach would provide adequate exposure and limit the morbidity of a Le Fort I osteotomy with palatal split.

\section{Transoral Approaches for Intradural Pathology}

With popularization of the transoral approach for extradural bony decompression in the late 1980s, some practitioners expanded the indications of the approach to include resection of purely intradural tumors located ventrally at the level of the clivus or foramen magnum. ${ }^{11,13}$ In the only series to date, in 1991 Crockard and Sen reported 7 patients who underwent a transoral approach for intradural pathology. ${ }^{13}$ There were substantial complications, including CSF leakage and infection. A watertight closure of the clival dura mater is difficult to nearly impossible. Therefore, all patients experienced CSF leaks, which required CSF diversion, packing, and reconstruction. Even with this, 5 ultimately required lumboperitoneal shunt- ing. The posterolateral-far lateral transcondylar approach to the ventral foramen magnum and upper cervical spine is a classic approach that limits CSF leakage and allows adequate visualization for resection of intradural pathology located ventrally and ventrolaterally at the level of the foramen magnum and upper cervical spine. ${ }^{68}$ With these results, the use of the transoral approach for intradural pathology was mostly abandoned.

\section{Complications Associated With Transoral Approaches}

In the hands of experienced surgeons, transoral complications are minimal. ${ }^{69}$ In the senior author's series ${ }^{69}$ of 280 children younger than 16 years who underwent the transoral approach to the posterior pharyngeal wall, there was no episode of CSF leakage $(0 \%)$ or meningitis $(0 \%)$. A pharyngeal wound dehiscence occurred in 2 children $(0.7 \%)$. In the first, the incision was reopened by inadvertent handling of a Yankauer suction tip 10 days after surgery. In the second, infection occurred, requiring intravenous antibiotics and drainage into the pharynx. Both of these complications occurred before 1990. Velopharyngeal insufficiency (VPI) was encountered in 5 children $(1.8 \%)$, was a particular problem in the young child, and usually occurred 3-6 months after the transoral operation, in cases in which the palate had been split. It was thought to be secondary to fibrosis that took place in the soft palate or in the pharyngeal wall. Endoscopy identified the cause. Pharyngeal retraining in 3 children and an obturator in the other 2 circumvented the problem. In 1 child, fat emulsion was injected into the posterior pharyngeal wall to bring it forward and close off the incompetence. This had to be repeated on 1 occasions. There were no deaths.

Similar complication rates have been seen in other series. In Choi and Crockard's series of 411 standard transoral approaches, ${ }^{9}$ pharyngeal wound infection occurred in $0.6 \%-1.1 \%$ of cases and dysphagia in $2.2 \%-3.3 \%$ of cases. A CSF leak occurred in $0.3 \%-1.1 \%$ of cases, and VPI occurred in $1.3 \%-14.3 \%$ of cases, with the higher percentage occurring in cases in which the soft palate was split.

\section{Advances in Neuroendoscopy}

The use of the endoscope in neurosurgical procedures began in the early 1900 s. $^{34}$ However, it wasn't until the technical advances in the 1970s, 1980s, and 1990s that the endoscope became useful and effective as a neurosurgical tool. ${ }^{34}$ Neuroendoscopy has emerged as an important adjunct to all types of neurosurgical procedures by extending the visualization of the neurosurgical approach beyond the tunnel vision of the operating microscope. ${ }^{52}$ The endoscope provides greater direct illumination with higher magnification in a deep operative field. With angled endoscopes, an angled line of sight can be achieved that brings into view previously hidden regions and areas typically blocked by the standard microscope..$^{18,19}$

\section{Endoscopic Transoral Approaches}

In 2002, Frempong-Boaudu et al. ${ }^{26}$ reported on 7 adults who underwent endoscopically assisted transoral surgery. 
This was the first report in which the endoscope was used in an assisted manner for transoral surgery. In all 7 patients satisfactory decompression of the CVJ was achieved and symptoms of cervicomedullary compression resolved or markedly improved in all previously symptomatic patients on serial clinic visits. Neurological status remained at baseline or was improved in all patients.

In 2006, Husain et al. ${ }^{40}$ published their series of 11 patients who underwent the endoscopic transoral approach for irreducible ventral CVJ pathology. The approach did not require forced excessive opening of the jaw, soft-palate splitting, or hard-palate resection. Two patients had posterior pharyngeal wall infections that were treated conservatively. In 2013, Yadav et al. ${ }^{102}$ published a series of 34 patients who underwent an endoscopic transoral approach for odontoidectomy. Exposure was achieved from the lower clivus to the $\mathrm{C} 2-3$ interspace in all cases, similar to the standard transoral-transpalatopharyngeal approach. The authors reported on advantages and disadvantages with the approach. Advantages included not having to divide the soft palate with use of a $30^{\circ}$ angled endoscope and that the procedure was done in patients with less than a $2.5-\mathrm{cm}$ mouth opening and in any neck position (flexion or extension). Disadvantages included difficulties in closure and in early postoperative oral feeding. Additionally, most patients in this series continued to experience some swallowing difficulties for 2-3 weeks. Others have used the endoscopic transoral approach and have found similar advantages and disadvantages. ${ }^{83}$

The endoscopic transoral approach has been effective at obviating the need to divide the soft palate. However, no direct comparison studies to the standard transoraltranspalatopharyngeal approach have been performed in regard to other advantages and disadvantages. Although the endoscopic transoral approach is an effective one, the emergence of the EEA to the CVJ has limited the widespread adoption of the former approach.

\section{Endoscopic Endonasal Approaches to the CVJ \\ Historical Beginnings}

The transsphenoidal approach to the sella turcica, based on the foundations laid by Hirsch and Cushing, is a procedure that began in the early 20th century but was plagued by CSF leakage and infection. ${ }^{48,54}$ The transsphenoidal approach popularized by Cushing was abandoned in the 1930s in the US for many years due to the significant risk of infection and the success of alternative transcranial approaches. ${ }^{54}$ With the help of antibiotics and better techniques, the risk of CSF rhinorrhea and meningitis was considerably reduced, and the transsphenoidal approach gained popularity again in the US in the 1970s. With better endoscopes providing better visualization to otorhinolaryngologists for the treatment of sinus disease, neurosurgeons adopted this instrument for the transsphenoidal approach and pituitary tumor resection. ${ }^{43}$ The endoscopic endonasal transsphenoidal approach for resection of sellar and parasellar pathology is now commonplace. ${ }^{1}$

In the last 20 years the EEA has been used in an extended fashion to resect extensions of sellar and parasel- lar masses, ${ }^{1}$ olfactory groove meningiomas, tuberculum sella meningiomas, craniopharyngiomas, ${ }^{27}$ petrous apex tumors, and clival tumors. ${ }^{19}$ In 2005, Kassam et al. published the first report of an EEA being used to perform an odontoidectomy. ${ }^{47}$ More recently, others have demonstrated the effectiveness of the EEA for the resection of ventral CVJ pathology in case reports and small case series. $5,21,28,31,36-38,41,49,51,56,80-82,84,90,95,101,103,106$

\section{Degree of CVJ Exposure}

The EEA provides a rostral and superior exposure from the anterior fossa floor to the superior aspect of the clivus. ${ }^{52}$ The caudal exposure is determined by the nasopalatine and palatine lines, and these have been shown to be important determinants in selecting the most appropriate candidates for the endonasal approach ${ }^{16,22}$ (Table 2).

\section{Indications and Limitations}

The standard transoral approach has proved effective for nearly 40 years in treating irreducible ventral CVJ pathology. ${ }^{69,75,77}$ The indications for the EEA are no different. The rostral exposure is limited by the relative location of the back of the hard palate to the CVJ pathology and ventral encroachment on the brainstem or upper cervical spinal cord. ${ }^{16,22}$ Additionally, in small children an endonasal approach may be limited by the small nares. ${ }^{46}$

\section{Effectiveness of the Approach}

Yu et al. ${ }^{106}$ reported on 3 patients who underwent an endoscopic endonasal odontoidectomy for basilar invagination. The authors used a posterior U-shaped nasopharyngeal flap to gain access to the clivus, anterior arch of $\mathrm{C}-1$, and the odontoid process. In all cases the incision was maintained above the oropharynx to potentially reduce infection risk. In addition, there was no need for soft-palate splitting or hard-palate resection, thus minimzing the risk of VPI. All 3 patients underwent posterior occipitocervical fusion and had neurological improvement postoperatively. A CSF leak was encountered in 1 case due to tight adherence of the odontoid process to the dura from long-standing compression. No infections were noted. Goldschlager et al. ${ }^{31}$ reported on 9 patients ( 7 adults and 2 children) who underwent an endoscopic endonasal odontoidectomy for various CVJ pathologies. The authors thought that the approach permitted early feeding by keeping the pharyngeal incision above the oropharynx and avoiding the need to divide the soft palate. No nasopharyngeal wound infections were noted. Other case series have been reported, all demonstrating findings similar to the ones discussed here.

\section{Comparison of the Endoscopic Endonasal and Standard Transoral Approaches}

Some studies have compared the standard transoral approach to the EEA in regard to CVJ exposure, outcomes, morbidity, and complications. ${ }^{82}$ Others have compared the approaches in cadavers. ${ }^{3}$ The advantages of the EEA include a decrease in tongue and oropharyngeal swelling and lack of a need for soft-palate division. This may lead to earlier extubation and decreased risks of VPI. Ad- 
ditionally, if the dissection stays within the nasopharynx and above the hard palate, oral feeding may begin earlier than with a transoral approach that divides the soft palate. Disadvantages of the EEA to the CVJ include a more limited caudal exposure compared with the standard transoral approaches, and the inability to close the posterior pharyngeal wall properly in a meticulous multilayered and anatomical fashion to limit infection.

Unlike EEAs to the cribriform plate, sella, petrous apex, and clivus, where dissection through the nasopharynx mucosa is thin, single layered, and without muscle attachment, the exposure of the inferior one-third of the clivus, C-1 anterior arch, and odontoid process requires dissection through multiple layers, including the nasopharyngeal mucosa and longus capitus and longus colli muscles, just as is done in the standard transoral approach. The type of closure that is completed endoscopically depends on the type of nasopharyngeal dissection performed to gain access to the $\mathrm{CVJ}$-an inverted U-shaped incision or a midline linear incision-and is difficult to close anatomically compared to the standard transoral approach. However, whether this nasopharyngeal dissection needs anatomical closure may not be important. By staying above the oropharynx and the path for oral nutrition, and without a soft-palate division, the risk of infection may be minimal, as is seen with other extended EEAs. However, if endoscopic endonasal access to the CVJ requires dissection through the oropharynx, infection risk may be increased. In this case, oral feedings should be delayed and a standard transoral approach in which the oropharynx can be closed in a multilayered anatomical fashion may be more appropriate.

\section{Summary of Approaches}

The main determinant of the appropriate ventral approach is the location of CVJ compression. The standard transoral approach has proved effective, with minimal complications and morbidity for treatment of all CVJ lesions that extend from the inferior aspect of the clivus to the C2-3 interspace. The emergence of the EEA obviates the need for division of the soft palate, with minimal tongue and oropharyngeal swelling, but is limited by the ability to meticulously and anatomically close the posterior pharyngeal wall. However, in cases that allow the dissection to stay above the oropharynx, meticulous anatomical closure appears to be less of a concern. The EEA to the CVJ is limited in cases in which the CVJ lesion and cervicomedullary compression are below the nasopalatine line and an oropharynx dissection is required. In these cases, a transoral approach may be more appropriate because it allows better caudal exposure than the EEA and an anatomical, meticulous posterior pharyngeal wall closure. The nasopalatine and palatine lines have been shown to be important determinants in selecting the most appropriate candidates for the endonasal approach. ${ }^{16,22}$ When the EEA fails to provide full exposure of the CVJ pathology, it may be combined with the transoral approach or the transoral approach can be used in isolation.

The EEA has essentially eliminated the need for extended transoral transmaxillary approaches to lesions ex- tending from the clivus to the CVJ. However, the transoral approach with MLG is still needed for rare congenital, acquired, or developmental pathology (Fig. 4) that extends inferiorly from the clivus to below the rostral exposure of the standard transoral approach or EEA. In summary, the best approach therefore needs to be individualized and tailored for each patient, whether adult or child.

\section{Reduction Strategies for CVJ Lesions Skeletal Traction Reduction}

Although the CVJ treatment algorithm (Fig. 1) has stood the test of time, the ability to reduce ventral CVJ lesions and avoid a ventral approach has increased since the late 1970s due to improvements in occipitocervical instrumentation, preoperative and intraoperative imaging, and a better understanding of CVJ pathology. This has resulted in a decrease in the number of cases requiring a transoral approach over the last 40 years. Bedside preoperative skeletal traction has been the most common method for reduction, but reduction may take days while the patient is admitted and bedbound. In children, skeletal traction often requires intubation and sedation. Being immobile and confined to the bed, in addition to the use of narcotics, sedation, and intubation all increase morbidity. Because of this morbidity, improved techniques for reduction have been developed.

\section{Distraction Reduction}

The use of distraction reduction has been used intraoperatively with occipitocervical instrumentation. ${ }^{39,44,59,104}$ Distraction may be conducted using instrumentation between the occipital bone plate/screws and $\mathrm{Cl}-2$ vertebral instrumentation or with distraction between $\mathrm{C}-1$ and $\mathrm{C}-2$ when $\mathrm{C}-1$ is congenitally fused with the occiput (atlas assimilation or occipitalization of the atlas) to increase the distance between the clivus and odontoid, allowing reduction and/or reducing dislocation. ${ }^{39,44,59,104}$ Others have used titanium spacers and bone graft to distract between the joints of $\mathrm{C}-1$ and $\mathrm{C}-2$ to treat basilar invagination. ${ }^{29}$ Purely intraoperative posterior distraction techniques can be effective for reduction of mild and moderate cases of basilar invagination. However, this approach requires commitment to a posterior-only approach and necessitates proper reduction through distraction prior to occipitocervical fixation. Instrumentation and fixation with improper reduction and therefore persistence of ventral compression can be problematic. Proper intraoperative imaging should be performed to provide evidence of reduction and decompression prior to occipitocervical fixation. If reduction cannot be achieved, a $540^{\circ}$ procedure may be necessary in some cases (depending on the pathology), whereby the posterior approach and incision is temporarily closed and the patient is repositioned supine for a ventral decompression followed by reopening of the posterior incision and posterior fixation.

\section{Neuromuscular Blockade, Intraoperative Traction, and 3D CT}

We've established an intraoperative rather than preoperative approach to reduce CVJ pathology (Fig. 5) $)^{14,15}$ that 


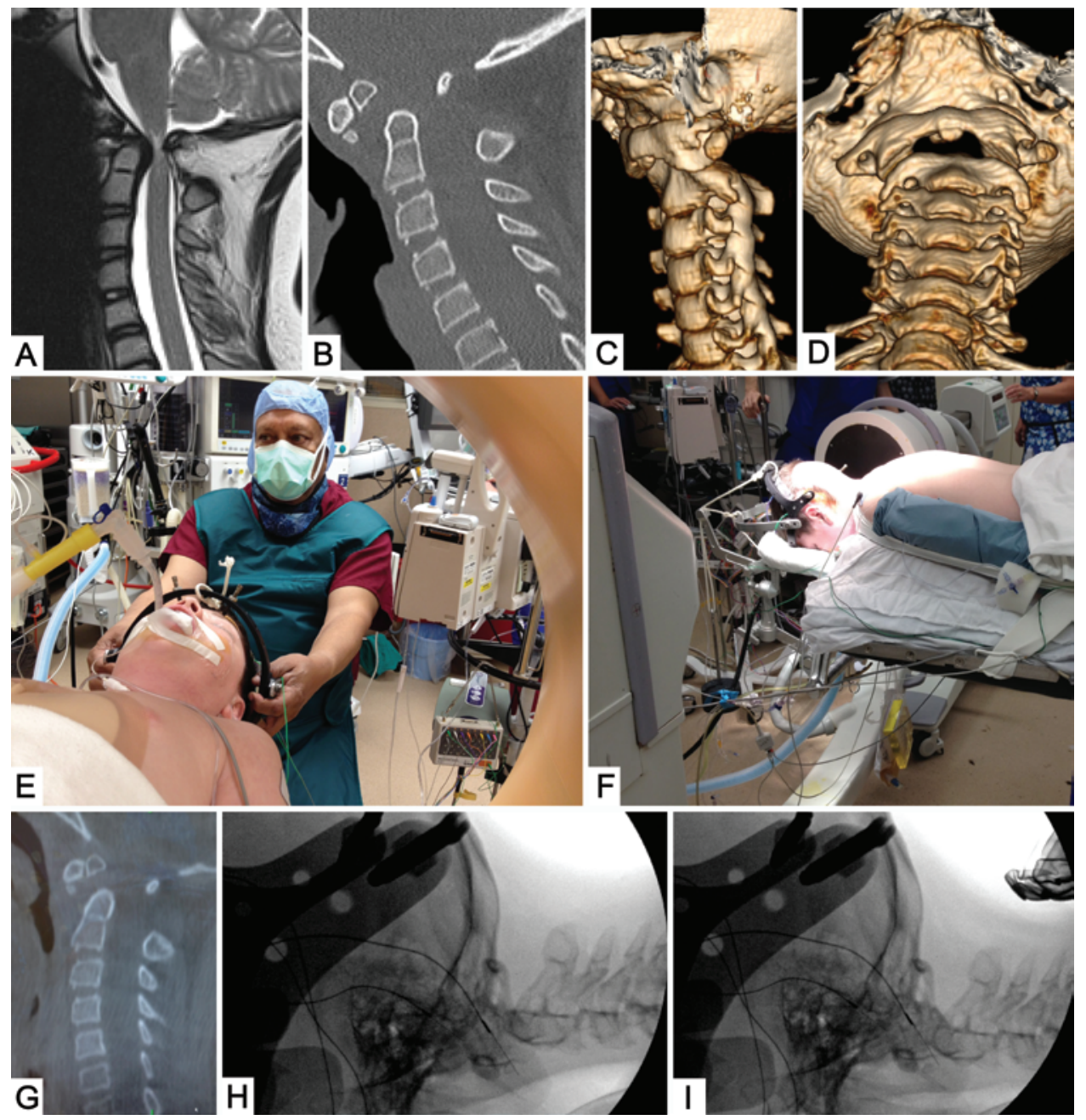

FIG. 5. Neuromuscular blockade and intraoperative traction with 3D CT images for confirmation of reduction. Cervical T2weighted MRI revealing severe cervicomedullary compression from the posterior arch of C-1 (A). Sagittal CT revealing dystopic os odontoideum with subluxation of C-1 on C-2 (B). A 3D CT scan revealing a component of C1-2 rotatory subluxation (C and D). General anesthesia and neuromuscular blockade with crown halo traction $(E)$. Prone positioning $(F)$ after reduction verified using intraoperative CT (G). Cervical fluoroscopic image (H) demonstrating reduction with traction (I).

obviates the need for prolonged bedside skeletal traction, eliminates the concern over the need for a $540^{\circ}$ procedure, and allows confirmation of reduction prior to committing to an anterior or posterior approach. Our approach is described here.

All patients undergo neck flexion/extension MRI of the CVJ to document reducibility with head position, and to determine what position is optimal for occipitocervical fixation. ${ }^{77}$ However, fusion when a patient's neck is in significant extension or flexion should be avoided because it does not provide a satisfactory reduction position. There are compensatory and potentially pathological changes that occur with fusion in hyperextension. Additionally, fusion in hyperflexion may lead to respiratory and swallowing difficulties.

The patient is brought to the operating room, where fiberoptic intubation is performed and general anesthesia is induced. Complete neuromuscular blockade is achieved using rocuronium, and somatosensory evoked potential monitoring is used. The crown halo is applied with the patient supine and the head is placed on a horseshoe headrest with $8 \mathrm{lbs}$ of traction (Fig. 5E). Using the O-arm (Medtronic, Inc.), an intraoperative 3D CT of the CCJ is obtained in traction and the amount of reduction and decompression at the $\mathrm{CMJ}$, along with the new clivus canal angle and new alignment, are all evaluated (Fig. 5E and $\mathrm{G})$. If there is adequate reduction and decompression with the neck in proper alignment, a transoral resection of the odontoid process is not needed. The patient is then placed prone, and another intraoperative 3D CT is obtained to verify adequate reduction, distraction of the odontoid process from the basiocciput, and an appropriate clivus canal angle (Fig. 5F). If this is satisfactory, a posterior fusion is performed (Fig. 6). Amount of traction can be varied based on the age and weight of the patient, degree of reduction needed, and type of CVJ pathology. This approach and technique for reduction has now been used for congenital or developmental basilar invagination, acute and chronic rotatory subluxation in children and adults, and in chronic dystopic os odontoideum. 


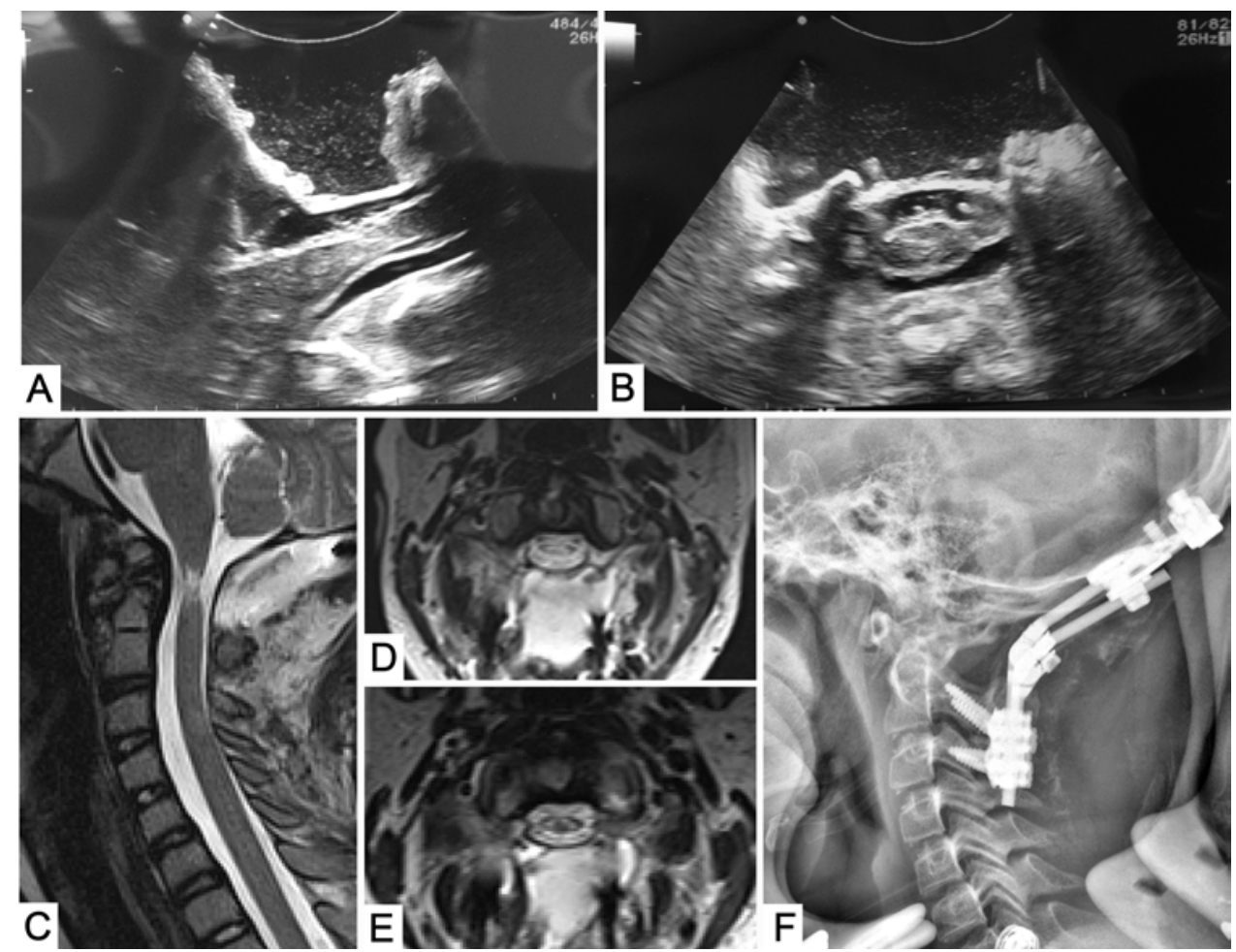

FIG. 6. Foramen magnum craniectomy and C-1 laminectomy with Oc-C3 fusion after reduction. Sagittal (A) and axial (B) ultrasound of the CMJ verifying reduction and decompression. Postoperative sagittal (C) and axial (D and E) cervical T2-weighted MRI revealing decompression of the CMJ. Postoperative lateral cervical radiograph (F) demonstrating Oc-C3 fusion.

\section{Neuromuscular Blockade, Intraoperative Traction, and 3D CT: Illustrative Case}

A 16-year-old boy was involved in a car accident at the age of 1.5 years, and by the age of 2 years was recognized to have difficulty with walking and climbing stairs and was unable to play. At that time, he was seen at another institution, where a child psychologist diagnosed attention deficit hyperactivity disorder and autism. His motor skills continued to decline, and 14 years later he was seen at the University of Iowa Hospitals and Clinics and found to be moderately spastic, quadriparetic, and grossly hyperreflexic, more in the lower extremities than in the upper extremities. Patellar reflexes were $3+$. He had bilateral Babinski reflexes with unsustained clonus in the ankles. Imaging revealed dystopic os odontoideum with anterior subluxation of $\mathrm{C}-1$ on $\mathrm{C}-2$, with rotatory subluxation revealing craniocervical instability and significant compression at the CMJ. There was marked hyperintense T2 signal intensity within the CMJ on MRI studies. Given the chronicity of the pathology, we used general anesthesia, neuromuscular blockade, and traction, with somatosensory evoked potential monitoring and $\mathrm{O}$-arm verification of reduction. The patient underwent posterior C-1 laminectomy, Oc-C3 fusion, and verification of reduction intraoperatively with fluoroscopy and ultrasound (Figs. 5 and 6).

\section{Update of the CVJ Treatment Algorithm}

The treatment of CVJ pathology has improved based on evolutions in transoral approaches and EEAs to the CVJ, better strategies to reduce and decompress neural struc- tures by using various forms of traction and reduction distraction techniques, and better preoperative and intraoperative imaging. Incorporating these advances, we updated the treatment algorithm for osseoligamentous CVJ pathology that results in CVJ instability (occipitoatlantal instability, atlantoaxial instability, or occipitoatlantoaxial instability) or cervicomedullary compression (Fig. 7). Osseoligamentous CVJ pathology is often associated with Chiari I malformation. ${ }^{66}$ Although reduction ${ }^{25,66}$ or ventral decompression may treat the osseoligamentous pathology, ${ }^{60}$ a dorsal decompression may still be warranted in each case to treat the Chiari malformation or to ensure complete cervicomedullary decompression. The algorithm is a general guide for CVJ pathology and should be used as such when determining the appropriate treatment strategy for each patient.

\section{Conclusions}

The emergence of the transoral approach in the late 1970s changed the course of CVJ treatment, allowing - for the first time-decompression of irreducible CVJ pathology. The validity of this approach allowed the institution of an algorithm for treatment of CVJ pathology. The standard transoral approach led to extended transoral approaches for expanded exposure to treat rare, large, congenital, developmental, and acquired CVJ pathology. The EEAs have evolved to treat CVJ pathology and provide certain advantages and disadvantages to the standard transoral approach. An evolution in reduction strategies now allows avoidance of a ventral decompression in many cases. In 


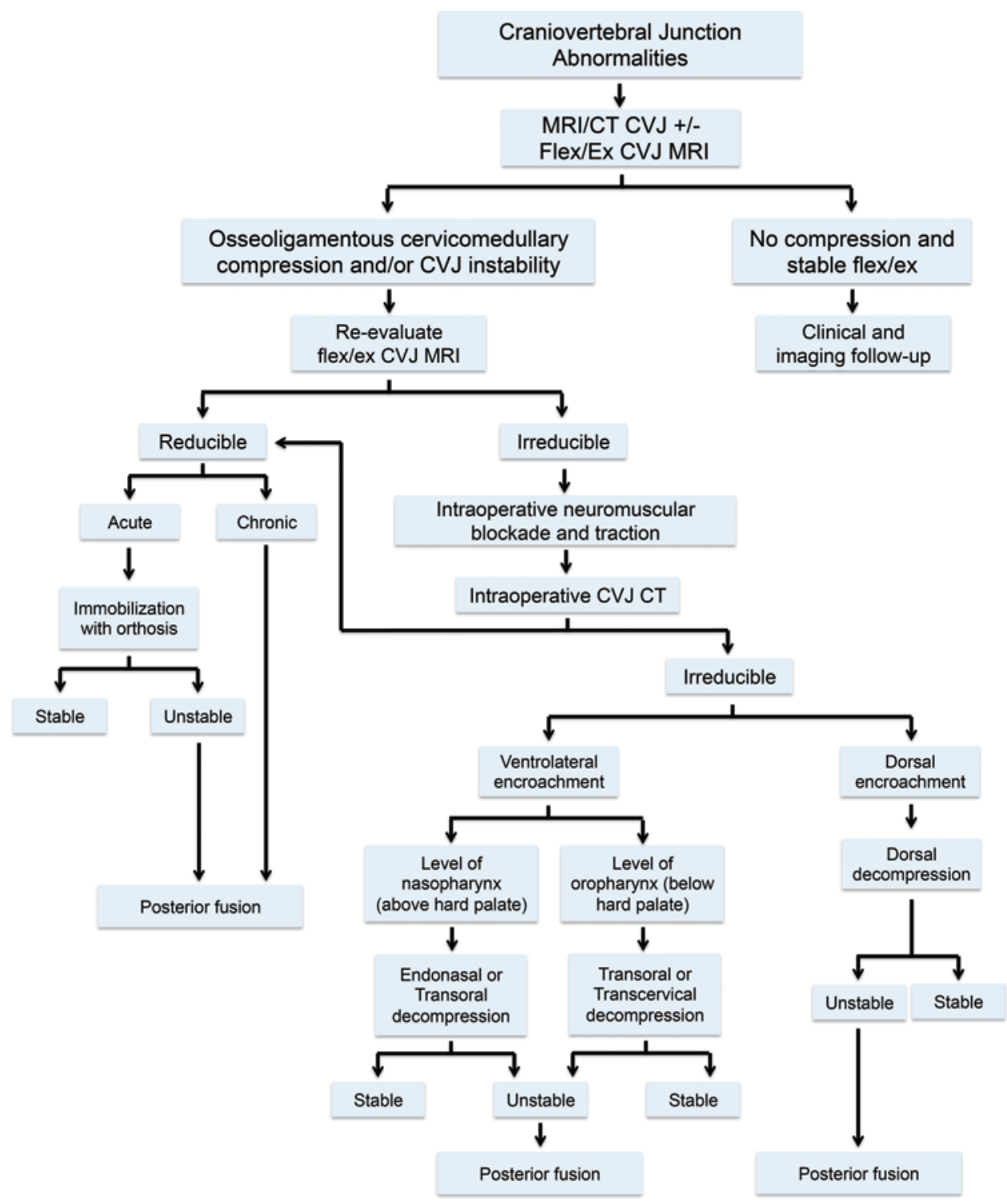

FIG. 7. Updated CVJ treatment algorithm. This is an updated treatment algorithm for osseoligamentous CVJ pathology that results in craniovertebral instability (occipitoatlantal instability, atlantoaxial instability, or occipitoatlantoaxial instability) or cervicomedullary compression. Advancements in understanding of CVJ pathology, ventral approaches, and reduction strategies have been incorporated into the algorithm. Craniovertebral junction pathologies can often be associated with a Chiari Type I malformation. This may warrant posterior decompression in addition to treatment of the osseoligamentous pathology. Flex/ex = flexion-extension.

this era of surgical subspecialization, to treat complex CVJ pathology properly, the CVJ surgeon must be trained in skull base transoral approaches and EEAs, pediatric and adult CVJ spinal procedures, and must understand and be able to treat the complex CSF dynamics present in CVJ pathology to provide the appropriate, optimal, and tailored treatment strategy for each individual patient, both child and adult.

\section{References}

1. Alfieri A: Endoscopic endonasal transsphenoidal approach to the sellar region: technical evolution of the methodology and refinement of a dedicated instrumentation. J Neurosurg Sci 43:85-92, 1999

2. Arbit E, Patterson RH Jr: Combined transoral and median labiomandibular glossotomy approach to the upper cervical spine. Neurosurgery 8:672-674, 1981

3. Baird CJ, Conway JE, Sciubba DM, Prevedello DM, Quiñones-Hinojosa A, Kassam AB: Radiographic and anatomic basis of endoscopic anterior craniocervical decompression: a comparison of endonasal, transoral, and transcervical approaches. Neurosurgery 65 (6 Suppl):ons158-ons164, 2009

4. Balasingam V, Anderson GJ, Gross ND, Cheng CM, Noguchi A, Dogan A, et al: Anatomical analysis of transoral surgical approaches to the clivus. J Neurosurg 105:301-308, 2006

5. Beech TJ, McDermott AL, Kay AD, Ahmed SK: Endoscopic endonasal resection of the odontoid peg-case report and literature review. Childs Nerv Syst 28:1795-1799, 2012

6. Bonney G: Stabilization of the upper cervical spine by the transpharyngeal route. Proc R Soc Med 63:896-897, 1970

7. Bonney GL, Laurence M: Malignant destruction of the axis. Two-year survival. Proc R Soc Med 62:585-586, 1969 
8. Brookes JT, Smith RJ, Menezes AH, Smith MC: Median labiomandibular glossotomy approach to the craniocervical region. Childs Nerv Syst 24:1195-1201, 2008

9. Choi D, Crockard HA: Evolution of transoral surgery: three decades of change in patients, pathologies, and indications. Neurosurgery 73:296-304, 2013

10. Crockard HA: The transoral approach to the base of the brain and upper cervical cord. Ann R Coll Surg Engl 67:321-325, 1985

11. Crockard HA: Transoral surgery: some lessons learned. Br J Neurosurg 9:283-293, 1995

12. Crockard HA, Essigman WK, Stevens JM, Pozo JL, Ransford AO, Kendall BE: Surgical treatment of cervical cord compression in rheumatoid arthritis. Ann Rheum Dis 44:809816,1985

13. Crockard HA, Sen CN: The transoral approach for the management of intradural lesions at the craniovertebral junction: review of 7 cases. Neurosurgery 28:88-98, 1991

14. Dahdaleh NS, Dlouhy BJ, Menezes AH: Application of neuromuscular blockade and intraoperative $3 \mathrm{D}$ imaging in the reduction of basilar invagination. J Neurosurg Pediatr 9:119-124, 2012

15. Dahdaleh NS, Dlouhy BJ, Menezes AH: One-step fixation of atlantoaxial rotatory subluxation: technical note and report of three cases. World Neurosurg 80:e391-e395, 2013

16. de Almeida JR, Zanation AM, Snyderman CH, Carrau RL, Prevedello DM, Gardner PA, et al: Defining the nasopalatine line: the limit for endonasal surgery of the spine. Laryngoscope 119:239-244, 2009

17. Delgado TE, Garrido E, Harwick RD: Labiomandibular, transoral approach to chordomas in the clivus and upper cervical spine. Neurosurgery 8:675-679, 1981

18. Dlouhy BJ, Chae MP, Teo C: The supraorbital eyebrow approach in children: clinical outcomes, cosmetic results, and complications. J Neurosurg Pediatr 15:12-19, 2015

19. Dlouhy BJ, Dahdaleh NS, Greenlee JD: Emerging technology in intracranial neuroendoscopy: application of the NICO Myriad. Neurosurg Focus 30(4):E6, 2011

20. Drommer RB: The history of the "Le Fort I osteotomy." J Maxillofac Surg 14:119-122, 1986

21. Duntze J, Eap C, Kleiber JC, Théret E, Dufour H, Fuentes S, et al: Advantages and limitations of endoscopic endonasal odontoidectomy. A series of nine cases. Orthop Traumatol Surg Res 100:775-778, 2014

22. El-Sayed IH, Wu JC, Dhillon N, Ames CP, Mummaneni P: The importance of platybasia and the palatine line in patient selection for endonasal surgery of the craniocervical junction: a radiographic study of 12 patients. World Neurosurg 76:183-188, 2011

23. Fang HS, Ong GB: Direct anterior approach to the upper cervical spine. J Bone Joint Surg Am 44:1588-1604, 1962

24. Fenoy AJ, Menezes AH, Donovan KA, Kralik SF: Calcium pyrophosphate dihydrate crystal deposition in the craniovertebral junction. J Neurosurg Spine 8:22-29, 2008

25. Fenoy AJ, Menezes AH, Fenoy KA: Craniocervical junction fusions in patients with hindbrain herniation and syringohydromyelia. J Neurosurg Spine 9:1-9, 2008

26. Frempong-Boadu AK, Faunce WA, Fessler RG: Endoscopically assisted transoral-transpharyngeal approach to the craniovertebral junction. Neurosurgery 51 (5 Suppl):S60-S66, 2002

27. Gardner PA, Kassam AB, Snyderman CH, Carrau RL, Mintz $\mathrm{AH}, \mathrm{Grahovac} \mathrm{S}$, et al: Outcomes following endoscopic, expanded endonasal resection of suprasellar craniopharyngiomas: a case series. J Neurosurg 109:6-16, 2008

28. Gempt J, Lehmberg J, Grams AE, Berends L, Meyer B, Stoffel M: Endoscopic transnasal resection of the odontoid: case series and clinical course. Eur Spine J 20:661-666, 2011

29. Goel A: Treatment of basilar invagination by atlantoaxial joint distraction and direct lateral mass fixation. J Neurosurg Spine 1:281-286, 2004

30. Goel A, Bhatjiwale M, Desai K: Basilar invagination: a study based on 190 surgically treated patients. J Neurosurg 88:962-968, 1998

31. Goldschlager T, Härtl R, Greenfield JP, Anand VK, Schwartz TH: The endoscopic endonasal approach to the odontoid and its impact on early extubation and feeding. J Neurosurg 122:511-518, 2015

32. Greenberg AD, Scoville WB, Davey LM: Transoral decompression of atlanto-axial dislocation due to odontoid hypoplasia. Report of two cases. J Neurosurg 28:266-269, 1968

33. Greenlee JD, Donovan KA, Hasan DM, Menezes AH: Chiari I malformation in the very young child: the spectrum of presentations and experience in 31 children under age 6 years. Pediatrics 110:1212-1219, 2002

34. Grosvenor AE, Laws ER: The evolution of extracranial approaches to the pituitary and anterior skull base. Pituitary 11:337-345, 2008

35. Hadley MN, Spetzler RF, Sonntag VKH: The transoral approach to the superior cervical spine. A review of 53 cases of extradural cervicomedullary compression. J Neurosurg 71:16-23, 1989

36. Hankinson TC, Grunstein E, Gardner P, Spinks TJ, Anderson RC: Transnasal odontoid resection followed by posterior decompression and occipitocervical fusion in children with Chiari malformation Type I and ventral brainstem compression. J Neurosurg Pediatr 5:549-553, 2010

37. Hansen MA, da Cruz MJ, Owler BK: Endoscopic transnasal decompression for management of basilar invagination in osteogenesis imperfecta. J Neurosurg Spine 9:354-357, 2008

38. Hickman ZL, McDowell MM, Barton SM, Sussman ES, Grunstein E, Anderson RC: Transnasal endoscopic approach to the pediatric craniovertebral junction and rostral cervical spine: case series and literature review. Neurosurg Focus 35(2):E14, 2013

39. Hsu W, Zaidi HA, Suk I, Gokaslan ZL, Wolinsky JP: A new technique for intraoperative reduction of occipitocervical instability. Neurosurgery 66 (6 Suppl Operative):319-324, 2010

40. Husain M, Rastogi M, Ojha BK, Chandra A, Jha DK: Endoscopic transoral surgery for craniovertebral junction anomalies. Technical note. J Neurosurg Spine 5:367-373, 2006

41. Iacoangeli M, Gladi M, Alvaro L, Di Rienzo A, Specchia N, Scerrati M: Endoscopic endonasal odontoidectomy with anterior $\mathrm{C} 1$ arch preservation in elderly patients affected by rheumatoid arthritis. Spine J 13:542-548, 2013

42. James D, Crockard HA: Surgical access to the base of skull and upper cervical spine by extended maxillotomy. Neurosurgery 29:411-416, 1991

43. Jho HD, Carrau RL: Endoscopic endonasal transsphenoidal surgery: experience with 50 patients. J Neurosurg 87:44-51, 1997

44. Jian FZ, Chen Z, Wrede KH, Samii M, Ling F: Direct posterior reduction and fixation for the treatment of basilar invagination with atlantoaxial dislocation. Neurosurgery 66:678-687, 2010

45. Kanavel AB: Bullet located between the atlas and the base of the skull: technique of removal through the mouth. Surg Clin Chicago 1:361-366, 1917

46. Kassam A, Thomas AJ, Snyderman C, Carrau R, Gardner P, Mintz A, et al: Fully endoscopic expanded endonasal approach treating skull base lesions in pediatric patients. J Neurosurg 106 (2 Suppl):75-86, 2007

47. Kassam AB, Snyderman C, Gardner P, Carrau R, Spiro R: The expanded endonasal approach: a fully endoscopic transnasal approach and resection of the odontoid process: technical case report. Neurosurgery 57:E213, 2005

48. Lanzino G, Laws ER Jr: Pioneers in the development of 
transsphenoidal surgery: Theodor Kocher, Oskar Hirsch, and Norman Dott. J Neurosurg 95:1097-1103, 2001

49. Laufer I, Greenfield JP, Anand VK, Härtl R, Schwartz TH: Endonasal endoscopic resection of the odontoid process in a nonachondroplastic dwarf with juvenile rheumatoid arthritis: feasibility of the approach and utility of the intraoperative Iso-C three-dimensional navigation. Case report. J Neurosurg Spine 8:376-380, 2008

50. Lawton MT, Beals SP, Joganic EF, Han PP, Spetzler RF: The transfacial approaches to midline skull base lesions: a classification scheme. Oper Tech Neurosurg 2:201-217, 1999

51. Leng LZ, Anand VK, Hartl R, Schwartz TH: Endonasal endoscopic resection of an os odontoideum to decompress the cervicomedullary junction: a minimal access surgical technique. Spine (Phila Pa 1976) 34:E139-E143, 2009

52. Lindley T, Greenlee JD, Teo C: Minimally invasive surgery (endonasal) for anterior fossa and sellar tumors. Neurosurg Clin N Am 21:607-620, v, 2010

53. Liu JK, Couldwell WT, Apfelbaum RI: Transoral approach and extended modifications for lesions of the ventral foramen magnum and craniovertebral junction. Skull Base 18:151166,2008

54. Liu JK, Das K, Weiss MH, Laws ER Jr, Couldwell WT: The history and evolution of transsphenoidal surgery. J Neurosurg 95:1083-1096, 2001

55. Martin H, Tollefsen HR, Gerold FP: Median labiomandibular glossotomy. Trotter's median (anterior) translingual pharyngotomy. Am J Surg 102:753-759, 1961

56. Mazzatenta D, Zoli M, Mascari C, Pasquini E, Frank G: Endoscopic endonasal odontoidectomy: clinical series. Spine (Phila Pa 1976) 39:846-853, 2014

57. Menezes AH: The anterior midline approach to the craniocervical region in children. Pediatr Neurosurg 18:272-281, 1992

58. Menezes AH: Complications of surgery at the craniovertebral junction-avoidance and management. Pediatr Neurosurg 17:254-266, 1991-1992

59. Menezes AH: Craniocervical fusions in children. J Neurosurg Pediatr 9:573-585, 2012

60. Menezes AH: Craniovertebral junction abnormalities with hindbrain herniation and syringomyelia: regression of syringomyelia after removal of ventral craniovertebral junction compression. J Neurosurg 116:301-309, 2012

61. Menezes AH: Craniovertebral junction anomalies: diagnosis and management. Semin Pediatr Neurol 4:209-223, 1997

62. Menezes AH: Craniovertebral junction database analysis: incidence, classification, presentation, and treatment algorithms. Childs Nerv Syst 24:1101-1108, 2008

63. Menezes AH: Honored guest presentation: conception to implication: craniocervical junction database and treatment algorithm. Clin Neurosurg 52:154-162, 2005

64. Menezes AH: Nosographic identification and management of pediatric craniovertebral junction anomalies: evolution of concepts and modalities of treatment. Adv Tech Stand Neurosurg 40:3-18, 2014

65. Menezes AH: Pathogenesis, dynamics, and management of os odontoideum. Neurosurg Focus 6(6):E2, 1999

66. Menezes AH: Primary craniovertebral anomalies and the hindbrain herniation syndrome (Chiari I): data base analysis. Pediatr Neurosurg 23:260-269, 1995

67. Menezes AH: Specific entities affecting the craniocervical region: Down's syndrome. Childs Nerv Syst 24:1165-1168, 2008

68. Menezes AH: Surgical approaches: postoperative care and complications "posterolateral-far lateral transcondylar approach to the ventral foramen magnum and upper cervical spinal canal." Childs Nerv Syst 24:1203-1207, 2008

69. Menezes AH: Surgical approaches: postoperative care and complications "transoral-transpalatopharyngeal approach to the craniocervical junction." Childs Nerv Syst 24:11871193,2008

70. Menezes AH, Fenoy KA: Remnants of occipital vertebrae: proatlas segmentation abnormalities. Neurosurgery 64:945954, 2009

71. Menezes AH, Graf CJ, Hibri N: Abnormalities of the craniovertebral junction with cervico-medullary compression. A rational approach to surgical treatment in children. Childs Brain 7:15-30, 1980

72. Menezes AH, Ryken TC: Craniovertebral abnormalities in Down's syndrome. Pediatr Neurosurg 18:24-33, 1992

73. Menezes AH, Traynelis VC: Anatomy and biomechanics of normal craniovertebral junction (a) and biomechanics of stabilization (b). Childs Nerv Syst 24:1091-1100, 2008

74. Menezes AH, Traynelis VC, Gantz BJ: Surgical approaches to the craniovertebral junction. Clin Neurosurg 41:187-203, 1994

75. Menezes AH, VanGilder JC: Transoral-transpharyngeal approach to the anterior craniocervical junction. Ten-year experience with 72 patients. J Neurosurg 69:895-903, 1988

76. Menezes AH, VanGilder JC, Clark CR, el-Khoury G: Odontoid upward migration in rheumatoid arthritis. An analysis of 45 patients with "cranial settling." J Neurosurg 63:500-509, 1985

77. Menezes AH, VanGilder JC, Graf CJ, McDonnell DE: Craniocervical abnormalities. A comprehensive surgical approach. J Neurosurg 53:444-455, 1980

78. Menezes AH, Vogel TW: Specific entities affecting the craniocervical region: syndromes affecting the craniocervical junction. Childs Nerv Syst 24:1155-1163, 2008

79. Moore LJ, Schwartz HC: Median labiomandibular glossotomy for access to the cervical spine. J Oral Maxillofac Surg 43:909-912, 1985

80. Nayak JV, Gardner PA, Vescan AD, Carrau RL, Kassam AB, Snyderman $\mathrm{CH}$ : Experience with the expanded endonasal approach for resection of the odontoid process in rheumatoid disease. Am J Rhinol 21:601-606, 2007

81. Patel AJ, Boatey J, Muns J, Bollo RJ, Whitehead WE, Giannoni CM, et al: Endoscopic endonasal odontoidectomy in a child with chronic type 3 atlantoaxial rotatory fixation: case report and literature review. Childs Nerv Syst 28:1971-1975, 2012

82. Ponce-Gómez JA, Ortega-Porcayo LA, Soriano-Barón HE, Sotomayor-González A, Arriada-Mendicoa N, GómezAmador JL, et al: Evolution from microscopic transoral to endoscopic endonasal odontoidectomy. Neurosurg Focus 37(4):E15, 2014

83. Qiuhang Z, Feng K, Bo Y, Hongchuan G, Mingchu L, Ge $\mathrm{C}$, et al: Transoral endoscopic odontoidectomy to decompress the cervicomedullary junction. Spine (Phila Pa 1976) 38:E901-E906, 2013

84. Rawal RB, Shah RN, Zanation AM: Endonasal odontoidectomy for basilar impression and brainstem compression due to radiation fibrosis. Laryngoscope 123:584-587, 2013

85. Ryken TC, Menezes AH: Cervicomedullary compression by separate atlantal lateral mass. Pediatr Neurosurg 19:165168,1993

86. Ryken TC, Menezes AH: Cervicomedullary compression in achondroplasia. J Neurosurg 81:43-48, 1994

87. Sandor GK, Charles DA, Lawson VG, Tator CH: Trans oral approach to the nasopharynx and clivus using the Le Fort I osteotomy with midpalatal split. Int J Oral Maxillofac Surg 19:352-355, 1990

88. Sasaki CT, Lowlicht RA, Astrachan DI, Friedman CD, Goodwin WJ, Morales M: Le Fort I osteotomy approach to the skull base. Laryngoscope 100:1073-1076, 1990

89. Scaramella LF: Median labiomandibular glossotomy. Laryngoscope 74:1561-1569, 1964

90. Sinha S, Mirza S, Bishop N, Zaki H, McMullan J: Endoscopic endonasal resection of the odontoid peg for paediatric basilar invagination. Br J Neurosurg 26:487-489, 2012 
91. Smith JS, Shaffrey CI, Abel MF, Menezes AH: Basilar invagination. Neurosurgery 66 (3 Suppl):39-47, 2010

92. Southwick WO, Robinson RA: Surgical approaches to the vertebral bodies in the cervical and lumbar regions. J Bone Joint Surg Am 39-A:631-644, 1957

93. Taggard DA, Menezes AH, Ryken TC: Instability of the craniovertebral junction and treatment outcomes in patients with Down's syndrome. Neurosurg Focus 6(6):E3, 1999

94. Thompson H: Transpharyngeal fusion of the upper cervical spine. Proc R Soc Med 63:893-896, 1970

95. Tomazic PV, Stammberger H, Mokry M, Gerstenberger C, Habermann W: Endoscopic resection of odontoid process in Arnold Chiari malformation type II. B-ENT 7:209-213, 2011

96. Uttley D, Moore A, Archer DJ: Surgical management of midline skull-base tumors: a new approach. J Neurosurg 71 (5 Pt 1):705-710, 1989

97. Vogel TW, Dlouhy BJ, Menezes AH: Craniovertebral junction abnormality in a case of Joubert syndrome. Childs Nerv Syst 28: 1109-1112, 2012

98. Wessberg GA, Hill SC, McBride KL: Median labiomandibular glossotomy. Int J Oral Surg 10:333-337, 1981

99. Williams WG, Lo LJ, Chen YR: The Le Fort I-palatal split approach for skull base tumors: efficacy, complications, and outcome. Plast Reconstr Surg 102:2310-2319, 1998

100. Wood GD, Stell PM: Osteotomy at the Le Fort I level. A versatile procedure. Br J Oral Maxillofac Surg 27:33-38, 1989

101. Wu JC, Huang WC, Cheng H, Liang ML, Ho CY, Wong TT, et al: Endoscopic transnasal transclival odontoidectomy: a new approach to decompression: technical case report. Neurosurgery 63 (1 Suppl 1): ONSE92-ONSE94, 2008

102. Yadav YR, Madhariya SN, Parihar VS, Namdev H, Bhatele PR: Endoscopic transoral excision of odontoid process in irreducible atlantoaxial dislocation: our experience of 34 patients. J Neurol Surg A Cent Eur Neurosurg 74:162167,2013

103. Yen YS, Chang PY, Huang WC, Wu JC, Liang ML, Tu TH, et al: Endoscopic transnasal odontoidectomy without resection of nasal turbinates: clinical outcomes of 13 patients. J Neurosurg Spine 21:929-937, 2014

104. Young RM, Sherman JH, Wind JJ, Litvack Z, O'Brien J: Treatment of craniocervical instability using a posterioronly approach: report of 3 cases. J Neurosurg Spine 21:239-248, 2014

105. Youssef AS, Sloan AE: Extended transoral approaches: surgical technique and analysis. Neurosurgery 66 (3 Suppl):126-134, 2010

106. Yu Y, Wang X, Zhang X, Hu F, Gu Y, Xie T, et al: Endoscopic transnasal odontoidectomy to treat basilar invagination with congenital osseous malformations. Eur Spine J 22:1127-1136, 2013

\section{Author Contributions}

Conception and design: Dlouhy. Acquisition of data: all authors. Analysis and interpretation of data: all authors. Drafting the article: Dlouhy. Critically revising the article: all authors. Reviewed submitted version of manuscript: all authors. Approved the final version of the manuscript on behalf of all authors: Dlouhy. Administrative/technical/material support: Menezes. Study supervision: Dlouhy, Menezes.

\section{Correspondence}

Brian J. Dlouhy, Department of Neurosurgery, University of Iowa Hospitals and Clinics, 200 Hawkins Dr., Iowa City, IA 52242. email: brian-dlouhy@uiowa.edu. 